VI PREMIO PARA JÓVENES

CONSTITUCIONALISTAS 



\section{PREMIO PARA JÓVENES CONSTITUCIONALISTAS»}

En el número 43 de nuestra revista se hicieron públicas las Bases de éste VI Premio para artículos científicos de jóvenes constitucionalistas.

Constituido el Jurado por los profesores de la disciplina: D. Óscar Alzaga Villaamil (Catedrático emérito de Derecho Constitucional de la UNED) quien actuó como Presidente, D. Luis Aguiar de Luque (Catedrático emérito de Derecho Constitucional de la Universidad Carlos III), D. ${ }^{a}$ Encarna Carmona Cuenca (Profesora Titular de Derecho Constitucional de la Universidad de Alcalá de Henares), D. ${ }^{a}$ Piedad García-Escudero Márquez (Catedrática de Derecho Constitucional de la Universidad Complutense de Madrid), D. Juan José Solozábal Echavarría (Catedrático emérito de Derecho Constitucional de la Universidad Autónoma de Madrid), D. David Ortega Gutiérrez (Catedrático de Derecho Constitucional de la Universidad Rey Juan Carlos), y D. Juan Manuel Goig Martínez (Catedrático de Derecho constitucional de la UNED) y — como Secretario con voz pero sin voto- D. Jorge Rafael Alguacil González-Auriores (Profesor Titular de Derecho Constitucional de la UNED), se acordó otorgar el primer premio al siguiente trabajo:

- Las cláusulas de restricción en el CEDH cuya autora, abierto el sobre de la plica, es D. ${ }^{a}$ Lara Redondo Saceda.

En la misma reunión se acordó otorgar accésits a los siguientes trabajos:

- El efecto vinculante de las sentencias de inconstitucionalidad frente al legislador cuya autora, abierto es sobre de la plica, es D. ${ }^{a}$ Elena Escobar Arbeláez.

- Teoría y práctica de la iniciativa legislativa popular cuya autor, abierto es sobre de la plica, es D. Ángel Fernández Silva.

- Función y disfunción de los elementos excepcionales en el sistema jurídico cuya autora, abierto es sobre de la plica, es D. ${ }^{a}$ Patricia García Majado. 



\title{
LAS CLÁUSULAS DE RESTRICCIÓN EN EL CONVENIO EUROPEO DE DERECHOS HUMANOS
}

\author{
LARA REDONDO SACEDA \\ Investigadora predoctoral FPU-MECD \\ Universidad de Alcalá
}

TRC, n. ${ }^{\circ} 47,2021$, pp. 469-492

ISSN 1139-5583

\section{SUMARIO}

I. Introducción. II. El punto de partida: ¿niveles de protección entre los derechos reconocidos en el CEDH?. III. La incorporación de las cláusulas de restricción al CEDH: un vistazo a los trabajos preparatorios. IV. Las cláusulas de restricción convencionales y sus diferencias: ¿distintos niveles de restricción?. V. El contenido de las cláusulas de restricción: la complejidad del case by case. VI. Un último apunte: el límite a las restricciones del artículo $18 \mathrm{CEDH}$. VII. Conclusiones.

\section{INTRODUCCIÓN}

En el año 2020 se cumplieron setenta años de la entrada en vigor del Convenio Europeo de Derechos Humanos (en adelante, CEDH, el Convenio o el Convenio Europeo). Además, acaban de cumplirse también los cuarenta años de la ratificación de España del $\mathrm{CEDH}^{1}$. Dos fechas que ponen de manifiesto la importancia del sistema europeo de protección de derechos humanos del Consejo de Europa y que sirven como punto de inflexión para reflexionar sobre cómo este sistema europeo ha crecido y evolucionado con la propia sociedad europea.

El presente trabajo versa sobre uno de los temas centrales relativos a la protección de derechos: la restricción a su ejercicio ${ }^{2}$. Setenta años de desarrollo del

1 BOE n..$^{\circ} 243$, de 10 de octubre de 1979, pp. 23564 a 23570.

2 El Convenio Europeo utiliza distintas expresiones para referirse a esta cuestión: injerencia de la autoridad pública (art. $8 \mathrm{CEDH}$ ), limitaciones (art. $9 \mathrm{CEDH})$, formalidades, condiciones, restricciones o sanciones (art. $10 \mathrm{CEDH}) \mathrm{y}$, de nuevo, restricciones (art. $11 \mathrm{CEDH})$. 
Convenio Europeo, a partir de la jurisprudencia del Tribunal Europeo de Derechos Humanos (en adelante, TEDH, el Tribunal o el Tribunal Europeo), han permitido configurar una delimitación importante de las cláusulas de restricción que integran el CEDH y que están formadas por los segundos párrafos de los artículos 8 - protección de la vida privada y familiar-, 9 - libertad de pensamiento, conciencia y religión —, 10 - libertad de expresión—y 11 —derecho de reunión y asociación-.

Si bien el desarrollo jurisprudencial de estos derechos ha sido muy prolífico y, además, ha sido objeto de estudio por parte de la doctrina europea y española, lo cierto es que hay pocos trabajos que aúnen el análisis de las cláusulas de restricción convencionales y su incidencia, en conjunto, en el sistema europeo de protección de derechos fundamentales ${ }^{3}$.

El objetivo de este artículo no es tanto incidir en el contenido de las cláusulas de restricción que configuran los segundos párrafos de los artículos 8 a 11 del CEDH —un tema desarrollado y profundizado por la doctrina-, sino reflexionar sobre si la existencia de estas cláusulas tienen efecto sobre la categorización y el ejercicio de los derechos que reconocen estos artículos, sobre cómo afectan - y si afectan - al lugar que ocupan estos derechos en el Convenio Europeo y qué las diferencia de otras limitaciones o exclusiones que integran los distintos artículos del CEDH. Pero, sobre todo, se quiere analizar la incidencia de estas cláusulas y su desarrollo jurisprudencial en la construcción del sistema europeo de derechos humanos articulado en el seno del Consejo de Europa.

Para ello el análisis que se propone se estructura en tres cuestiones. En primer lugar, reflexionar sobre la categorización de los derechos protegidos por los artículos 8 a 11 del CEDH como derechos restringidos, condicionales o qualified rights. En segundo lugar, retomar los trabajos preparatorios del Convenio Europeo y sus antecedentes para intentar analizar la inclusión de estas cláusulas y su objetivo. Por último, se pretende estudiar la configuración y arquitectura de estas cláusulas con el objeto de considerar cómo han afectado al desarrollo y ejercicio de los derechos reconocidos en estos artículos.

\section{EL PUNTO DE PARTIDA: ¿NIVELES DE PROTECCIÓN ENTRE LOS DERECHOS RECONOCIDOS EN EL CEDH?}

De acuerdo con Jacobs, White \& Ovey no existe, formalmente, una jerarquía entre los derechos que configuran el $\mathrm{CEDH}^{4}$. Esto es, el Convenio no

3 Quizás el trabajo más completo al respecto sea el del francés Vincent Coussirat-Coustere en Pettiti, L.E.; Decaux, E.; Imbert, P.H., La Convention Européenne des droits de l'homme, Economica: Paris, 1999.

4 White, R. C. A. y Ovey, C., Jacobs, White and Ovey, the European Convention on Human Rights, Oxford University Press, Oxford, 2010, pp. 8-9. 
establece distintos niveles de protección en función de los derechos reconocidos, sino que todos parecen gozar de la misma garantía ${ }^{5}$. Asimismo, el texto del Convenio Europeo no incluye ninguna disposición relativa a la prevalencia de un derecho sobre otro en caso de conflicto ${ }^{6}$. Es más, el propio artículo 1 del CEDH recoge la obligación general y negativa de los Estados contratantes de no afectar cualquiera de los derechos y libertades reconocidos a cualquier persona bajo su jurisdicción ${ }^{7} \sin$ reconocer la potestad a los Estados de decidir sobre qué derechos aplicar ni de elegir con qué nivel de protección dotar a cada uno de ellos, más allá de la posibilidad de incluir reservas a este tratado.

No obstante, estos principios generales parecen ser cuestionados por una parte de la doctrina. De un lado, Jane Wright afirma que los distintos derechos reconocidos y los estándares creados no solo a partir del Convenio Europeo, sino de la mayoría de los instrumentos internacionales de protección de derechos humanos, no siempre requieren el mismo grado de protección, pudiendo entender, con ello, que existe una cierta jerarquía de derechos en el $\mathrm{CEDH}^{9}$. De otro lado, Jacobs, White \& Ovey entienden que existe una aceptación general de que, ante un conflicto de derechos convencionales, es habitual que un interés prevalezca sobre otro y que, después de la debida ponderación, la protección de un derecho prime frente a la de otro ${ }^{10}$. Ahora bien, a diferencia de Wright, estos autores no identifican que esta situación dé lugar a una jerarquía entre los derechos del Convenio.

Sin embargo, sí parece existir una cierta tendencia doctrinal a clasificar los derechos del CEDH en relación con distintos niveles de protección. Es decir, aunque, salvo alguna excepción puntual — como se ha visto- , se entiende que no es posible hablar de una jerarquía entre los derechos convencionales, sí que se defiende la idea de es posible extraer del texto del Convenio Europeo distintos

5 En este sentido, cabe recordar que la Declaración de Viena y el Programa de Acción de Viena, aprobados por la Conferencia Mundial de Derechos Humanos el 25 de junio de 1993, recoge el deber de la comunidad internacional de tratar los derechos humanos de forma global, justa y equitativa, otorgando a todos el mismo peso (Parte I, apartado 5).

6 White, R. C. A. y Ovey, C., Jacobs, White and Ovey, op. cit, pp. 8-9.

7 Artículo $1 \mathrm{CEDH}$ : «Las Altas Partes Contratantes reconocen a toda persona bajo su jurisdicción los derechos y libertades definidos en el Título I del presente Convenio». Un análisis pormenorizado de este artículo puede leerse en Fernández Sánchez, P., «El alcance de las obligaciones del Convenio Europeo de Derechos Humanos», en García Roca, J. y Santolaya, P., La Europa de los Derechos, Centro de Estudios Políticos y Constitucionales, Madrid, 2014, pp. 43-56.

8 De conformidad con lo establecido en el propio artículo $57 \mathrm{CEDH}$ : «1. Todo Estado podrá formular, en el momento de la firma del presente Convenio o del depósito de su instrumento de ratificación, una reserva a propósito de una disposición particular del Convenio en la medida en que una ley en vigor en su territorio esté en desacuerdo con esta disposición. Este artículo no autoriza las reservas de carácter general. 2. Toda reserva formulada de conformidad con el presente artículo irá acompañada de una breve exposición de la ley de que se trate.» Sobre esta cuestión véase: Carrillo Salcedo, J.A., El Convenio Europeo de Derechos Humanos, Tecnos, Madrid, 2004, pp. 36-38.

9 Cfr. Wright, J., Tort Law and Human Rights, Hart Publishing, Oxford, 2017, pp. 95-96.

10 White, R. C. A. y Ovey, C,. ... the European Convention..., op. cit., pp. 8-9. 
niveles de protección de derechos ${ }^{11}$ : unqualified rights and qualified rights ${ }^{12}$. Bajo la categoría unqualified rights se agrupan los derechos garantizados por los artículos 2 a $7^{13}$ y 12 a $14 \mathrm{CEDH}^{14}$, además de los artículos 2 y 3 del Protocolo 1 , los artículos 1 y 2 del Protocolo $6^{15}$ y el artículo 1 del Protocolo $13^{16}$. Es decir, derechos intensamente protegidos, incluso algunos de ellos —artículos 2, 3 y párrafo primero del artículo 4 - no derogables y, aunque ciertamente limitados, puesto que no hay derechos absolutos ${ }^{17}$, su ejercicio no está sometido a restricciones que amparen una interferencia del poder público, al menos de manera específica en el texto del Convenio. En otro orden, los qualified rights agrupan los artículos 8 a 11 $\mathrm{CEDH}$, que contienen un apartado segundo en el que se prevé la posibilidad de que exista una injerencia pública que pueda restringir el ejercicio de los derechos reconocidos en estos artículos cuando exista previsión legal y finalidad legítima y cuando la medida sea necesaria en una sociedad democrática. También se incluyen aquí el artículo 1 del Protocolo 1 —derecho de propiedad- y el artículo 2 del Protocolo 4 - libertad de circulación-.

Siguiendo esta misma idea de que los derechos reconocidos en el CEDH deben clasificarse asumiendo distintos niveles de protección, Santiago Quesada Polo propone una clasificación en tres estadios: derechos inderogables, derechos mínimos y derechos restringidos ${ }^{18}$. En primer lugar, son «derechos inderogables» aquellos que conforman el «núcleo duro del Convenio» y que, en conexión con lo dispuesto en el artículo $15 \mathrm{CEDH}$, gozan de una protección reforzada ${ }^{19}$. En segundo lugar, los «derechos mínimos», donde se incluye la prohibición de tra-

11 Cfr. Almeida, S., Familia a la luz del Convenio Europeo de Derechos Humanos, Juruá Editorial, Lisboa, 2015, pp. 20 y 73; Wright, J., Tort Law and Human Rights... op. cit, pp. 95-96.

12 Son varios los autores que utilizan esta clasificación. Entre ellos, White, R. C. A. y Ovey, C. ...the European Convention..., op. cit., pp. 9-10; ROAGNA, I., Protecting the right to respect for private and family life under the European Convention on Human Rights, Council of Europe Human Rights Handbooks, Strasbourg, 2012, pp. 7, 9, 37, 42. Es más, el propio Consejo de Europa, en la guía de definiciones sobre el CEDH incluye esta clasificación y entiende que los qualified rights son aquellos derechos que pueden verse interferidos con el objetivo de proteger los derechos de otras personas o de garantizar un interés público. Por su parte, los unqualified rights son aquellos derechos que, aunque pueden verse sujetos a excepciones específicas, implican que no pueden verse afectados por intereses públicos y otros derechos individuales. Ver: ECRH Toolkit, Definitions. [consulta: febrero 2020]. Disponible en: https://www.coe.int/en/web/echr-toolkit/definitions

13 En orden: derecho a la vida, prohibición de tortura, prohibición de esclavitud y trabajos forzados, derecho a la libertad y la seguridad, derecho a un proceso equitativo y principio de legalidad penal.

14 En orden: derecho a contraer matrimonio, derecho a un recurso efectivo y prohibición de discriminación.

15 Derecho a la educación y derecho a elecciones libres.

16 Relativos a la abolición de la pena de muerte.

17 Salvo, como se acepta generalmente, la prohibición de tortura del artículo 3 CEDH, única disposición del Convenio que carece de excepciones o derogaciones.

18 Cfr. Quesada Polo, S., «El Convenio Europeo de Derechos Humanos. Apuntes sobre el sistema de control del Convenio», Anales de Derecho. Universidad de Murcia, n. ${ }^{\circ} 16,1998$, pp. 164-167.

19 Ibid. p. 165. Quesada Polo incluye en esta categoría los artículos 2 (derecho a la vida), 3 (prohibición de tortura), 4.1. (prohibición de esclavitud), 7 (principio de legalidad penal), 6 y 13 (derecho a un juicio justo y a un recurso efectivo). 
bajos forzados (art. 4.2 CEDH), el derecho a la libertad y la seguridad (art. 5 $\mathrm{CEDH}$ ), el derecho a un proceso equitativo (art. $6 \mathrm{CEDH}$ ), el derecho a contraer matrimonio y a formar una familia (art. $12 \mathrm{CEDH}$ ), el derecho a un recurso efectivo (art. $13 \mathrm{CEDH}$ ) y la prohibición de discriminación (art. 14 CEDH). En último lugar, los «derechos restringidos» ${ }^{20}$ vienen constituidos por el derecho al respeto de la vida privada y familiar (art. $8 \mathrm{CEDH}$ ), el derecho a libertad de pensamiento y religión (art. 9 CEDH), el derecho a la libertad de expresión (art. 10 $\mathrm{CEDH}$ ) y el derecho de reunión (art. $11 \mathrm{CEDH}$ ).

Ahora bien, parece necesario plantearse algunas cuestiones. Primero, qué justifica que determinados derechos del CEDH estén sometidos a estas cláusulas de restricción y cuáles son las consecuencias de ello. Segundo, no está de más reflexionar sobre si en la práctica estas clasificaciones doctrinales por niveles de protección implican una menor garantía de los llamados derechos restringidos o qualified rights en relación con ese llamado núcleo duro conformado por los unqualified rights.

\section{LA INCORPORACIÓN DE LAS CLÁUSULAS DE RESTRICCIÓN AL CEDH: UN VISTAZO A LOS TRABAJOS PREPARATORIOS ${ }^{21}$}

Comenzando por la primera cuestión, parece necesario apuntar que la inclusión de cláusulas de restricción en el Convenio Europeo no es una cuestión genuina y única, sino habitual en los textos internacionales de Derechos Humanos. De una parte, es cierto que la Declaración Universal de 1948 (en adelante, DUDH) no incluye este tipo de cláusulas en los derechos equivalentes reconocidos, al menos no de una forma tan explícita y detallada ${ }^{22}$. Pero sí es cierto que en su artículo 29 se incluye una cláusula general de restricción que afecta a todos los derechos de la Declaración: «1. Toda persona tiene deberes respecto a la comunidad, puesto que sólo en ella puede desarrollar libre y plenamente su personalidad. 2. En el ejercicio de sus derechos y en el disfrute de sus libertades, toda persona estará solamente sujeta a las limitaciones establecidas por la ley con el único fin de asegurar el reconocimiento y el respeto de los derechos y libertades de los demás, y de satisfacer las justas exigencias de la moral, del orden público y del bienestar general en una sociedad democrática. 3. Estos derechos y libertades no

20 Ibid. pp. 166-167.

21 Aunque en las siguientes páginas me limitaré a referirme a los artículos 8 a 11 del CEDH debe tenerse en cuenta que las consideraciones y reflexiones que se realizan en este texto son aplicables, también, a los artículos 1 del Protocolo 1 al CEDH (derecho de propiedad) y 2 del Protocolo 4 al CEDH (libertad de circulación). Ambos artículos tienen una estructura similar a la de los artículos 8 a 11 e, igualmente, son esferas importantes de intervención de los poderes públicos.

22 Solo el artículo 12 DUDH que protege el derecho a la vida privada, la familia, el domicilio y la correspondencia se limita a decir que «nadie será objeto de injerencias arbitrarias...». 
podrán, en ningún caso, ser ejercidos en oposición a los propósitos y principios de las Naciones Unidas.»

También el Pacto Internacional de Derechos Civiles y políticos integra cláusulas de restricción análogas a las del CEDH en su articulado ${ }^{23}$. Asimismo, la Convención Americana de Derechos Humanos (Pacto de San José, 1969) configura, igualmente, sus derechos equivalentes con cláusulas de restricción similares $^{24}$.

De otra parte, según Vicent Coussirat-Coustere, los derechos garantizados por los artículos 8 a 11 CEDH protegen intereses con una dimensión social importante que permiten asumir que los poderes públicos, como garantes del interés general y de las libertades ciudadanas, puedan intervenir en la regulación de su ejercicio ${ }^{25}$. Por tanto, desde esta perspectiva, la juridificación en el CEDH de la injerencia pública en el ejercicio de los derechos reconocidos parece ser una cuestión que se ampara en la legitimidad del propio poder público.

Ahora bien, ¿cuál fue la justificación original para incluir estas cláusulas de restricción? Durante los trabajos preparatorios del Convenio Europeo se abrió un debate importante sobre cómo configurar el ejercicio de los derechos y sus restricciones que condicionó en gran medida la preparación del borrador. Cuando la Asamblea Consultiva del Consejo de Europa envía al Comité de Ministros su propuesta para la elaboración de una convención europea de dere$\operatorname{chos}^{26}$, se propuso la inclusión de una cláusula general de restricción que seguía el modelo establecido por la DUDH y su artículo 29. No obstante, durante el trabajo del Comité de Expertos ${ }^{27}$ se pusieron de manifiesto posiciones opuestas sobre cómo enfocar la configuración del ejercicio de los derechos convencionales. Por un lado, Reino Unido defendía la necesidad de que los derechos del Convenio debían estar definidos de manera precisa para ser salvaguardados de manera efectiva, lo que incluía la definición de sus limitaciones y de la extensión de las

23 Ver artículo 17 (protección de la vida privada, familia, domicilio y correspondencia), artículo18 (derecho a la libertad de pensamiento, conciencia y religión), artículo 19 (libertad de expresión), artículo 21 (derecho de reunión y manifestación), artículo 22 (derecho de asociación).

24 Ver artículo 12 (libertad de conciencia y religión), artículo 15 (derecho de reunión), artículo 16 (libertad de asociación), artículo 21 (derecho a la propiedad privada), artículo 22 (derecho de circulación y residencia).

25 Cfr. Coussirat-Coustere, V., «Article 8 § 2» en Pettiti, L.E.; Decaux, E.; Imbert, P.H., $L a$ Convention Européenne des droits de l'homme, Economica, Paris, 1999, p. 323.

26 Mediante la Recomendación 38 de 1949, la Asamblea Consultiva del Consejo de Europa —hoy Asamblea Parlamentaria - aprueba el llamado Informe Teitgen desarrollado en el seno del Committee on Legal Affairs and Administrative Questions. Sobre este proceso ver: Council of Europe, Vol.1. Preparatory Commission of the Council of Europe, Committee of Ministers, Consultative Assembly (11 May - 8 September 1949) in Collected edition of the "Travaux préparatoires» of the European Convention on Human Right, The Hague: Council of Europe-Martinus Nijhoff, 1975.

27 Creado por el Comité de Ministros en noviembre de 1949 con el objetivo de preparar un proyecto de convención, este comité desarrolló su labor durante los meses de febrero y marzo de 1950 tomando como base la propuesta inicial enviada por la Asamblea Consultiva. Cfr. Council of Europe. Vol.1... ob.cit., p. XXVI. 
obligaciones de los Estados ${ }^{28}$. Por otro lado, Francia e Italia apostaban por un modelo más abierto y similar al implementado por la DUDH que evitara definiciones demasiado determinadas e incluyera unas reglas generales, puesto que consideraban que no era posible prever todos los supuestos de restricción que podrían llegar a ser necesarios ${ }^{29}$. Durante el período de presentación y debate de enmiendas, Reino Unido presentó el 6 de marzo de 1950 un borrador en el que ciertos artículos —asimilables a los artículos 8 a 11 actuales-quedaban divididos en dos párrafos: un primer párrafo en el que se reconocían los derechos y un segundo párrafo que incluía las condiciones de ejercicio de esos derechos y sus restricciones ${ }^{30}$.

Esta situación de confrontación llevó al Comité de Expertos a proponer al Comité de Ministros que decidiese entre dos posibilidades sobre las que no se consideraba capacitado para decidir ${ }^{31}$ : a) enumeración de derechos humanos ${ }^{32}$ y b) definición de derechos humanos ${ }^{33}$. Ante esta situación, el Comité de Ministros constituyó la Conference of Senior Officials ${ }^{34}$, que tomó la decisión de adoptar la alternativa b) como base de trabajo incluyendo dos principios generales que ayudaron a contar con el apoyo de los partidarios de la otra alternativa $\left.{ }^{35}: 1\right)$ todas las cláusulas de restricción contendrían la referencia «necesaria en una sociedad democrática» y 2) se articuló una cláusula general que prohibía que las restricciones a los derechos fundamentales tuvieran otro propósito distinto de aquel para que el que habían sido previstas (actual artículo 18) ${ }^{36}$. Además, la propuesta de la Conference of Senior Officials incluyó en el elenco de derechos el respeto de la vida privada y familiar, el domicilio y la correspondencia (actual artículo 8) que no se encontraba en el listado de la alternativa b). Esta decisión permitió una suerte de equilibrio entre el pragmatismo que implicaba la inclusión de cláusulas de restricción específicas y la introducción de un marco general de interferencia pública en el ejercicio de los derechos ${ }^{37}$.

28 Cfr. Council of Europe, Vol.3. Committee of Experts (2 February - 10 March 1950) in Collected edition of the «Travaux préparatoires» of the European Convention on Human Right The Hague: Council of Europe-Martinus Nijhoff, 1976, pp. 254-256.

29 Ibid. p. 256.

30 Ibid. pp. 286-288.

31 De acuerdo con el Comité de Expertos, la decisión sobre qué opción era la más conveniente debía tomarse conforme a criterios políticos que escapaban de su competencia. Cfr. Council of Europe, Vol.4. Committee of Experts - Committee of Ministers Conference of Senior Officials (30 March - 17 June 1950) in Collected edition of the "Travaux préparatoires» of the European Convention on Human Right, The Hague: Council of Europe-Martinus Nijhoff, 1977, pp. 16-18.

32 Identificable con la propuesta de los expertos francés e italiano. Cfr. Council of Europe, Vol.4 ...op. cit. pp. 17-30.

33 De conformidad con la propuesta del experto inglés. Cfr. Council of Europe, Vol.4...op. cit, pp. 30-42.

34 Esta Conferencia trabajó durante el mes de junio de 1950.

35 Council of Europe, Vol.4 ...ob.cit. p. 258.

36 Idem.

37 Coussirat-Coustere, V., «Article 8 § 2»... op. cit. p. 325. 


\section{LAS CLÁUSULAS DE RESTRICCIÓN CONVENCIONALES Y SUS DIFERENCIAS: ¿DISTINTOS NIVELES DE RESTRICCIÓN?}

Los segundos párrafos de los artículos 8 a 11CEDH establecen, con una redacción muy similar, que los derechos reconocidos en ellos no podrán verse interferidos por los poderes públicos salvo que exista previsión legal y que la medida de interferencia, en una sociedad democrática, sea necesaria para preservar la seguridad nacional y la seguridad pública, el bienestar económico del país, la defensa del orden y la prevención de las infracciones penales, la protección de la salud o de la moral y la protección de los derechos y libertades de los demás (art. 8.2 CEDH).

Si bien los cuatro artículos tienen una redacción similar, hay ciertas cuestiones que los diferencian. El artículo 9.2 CEDH — libertad de pensamiento, conciencia y religión - no incluye la injerencia amparada en la seguridad nacional, sino solo en la seguridad pública, y tampoco la que pueda justificarse en el bienestar económico del país ni en la prevención de las infracciones penales. Por su parte, el artículo 10.2 CEDH - libertad de expresión-especifica la injerencia como el posible sometimiento del ejercicio de los derechos reconocidos a formalidades, condiciones, restricciones e, incluso, sanciones. Pero, al mismo tiempo, este artículo añade la posibilidad de que, además de por las cuestiones anteriormente expuestas, la injerencia pública pueda estar justificada en la preservación de la integridad territorial, la protección de la reputación, impedir la divulgación de informaciones confidenciales y garantizar la autoridad e imparcialidad del poder judicial. Por último, el artículo 11.2 $\mathrm{CEDH}$ — derecho de reunión y asociación - añade una última medida: la posibilidad de que se impongan restricciones cuando quienes ejerzan los derechos reconocidos en ese artículo sean miembros de las fuerzas armadas, de la policía o de la Administración pública.

La cuestión a plantearse es cómo debemos entender estas diferencias: ¿se trata de niveles de restricción? Es decir, ¿el objetivo es dar a entender que el ejercicio de unos derechos está sometido a un control más estricto que el de otros? De acuerdo con Coussirat-Coustere, el objetivo de las cláusulas de restricción es proteger los derechos fundamentales mediante la subordinación de las injerencias a ciertas condiciones susceptibles de control por parte del TEDH ${ }^{38}$. Esto es, la configuración de estos segundos párrafos no está dirigida a someter los derechos a las restricciones, sino blindarlos frente a injerencias arbitrarias. Por tanto, parece posible entender que la restricción en sí misma puede revertirse hacia los Estados, limitando sus posibilidades de interferencia y su actuación en lugar de entender que es una restricción para el propio individuo titular del derecho.

Por otro lado, también parece necesario reflexionar sobre el impacto real de estas diferencias entre las distintas cláusulas de restricción. Si bien puede parecer

38 Coussirat-Coustere, V., «Article 8 § 2..» op. cit., p. 328. 
que el artículo $10 \mathrm{CEDH}$ queda más afectado por restricciones a su ejercicio debido a su redacción, lo cierto es que el impacto en el derecho no parece ser demasiado elevado ${ }^{39}$. De una parte, aunque no se especifica que el ejercicio de los otros derechos pueda quedar limitado por formalidades, condiciones, restricciones y sanciones, la previsión legal nacional que establezca la medida restrictiva bien puede ser una sanción o una condición. De otra parte, podría considerarse que si un Estado restringe el ejercicio de la libertad de expresión mediante la imposición de una sanción, esta no podría servir como represalia ${ }^{40}$, sino que el objetivo de la misma debe estar dirigido a proteger los intereses especificados en la cláusula de restricción convencional ${ }^{41}$. Con lo cual, el objetivo de las cláusula de restricción nunca será, en sí mismo, impedir el ejercicio del derecho, sino impedir, como se viene diciendo, una actuación del poder público dirigida a coartar el ejercicio del mismo.

Esta interpretación de las cláusulas de restricción permite entender, por tanto, que no estamos ante derechos con nivel de protección inferior al resto de los derechos del CEDH, sino que estamos ante derechos que por su propia especialidad e influencia social requieren un mayor control no del propio derecho, sino de la actuación del poder público, de manera que sea posible garantizar mejor su ejercicio.

\section{EL CONTENIDO DE LAS CLÁUSULAS DE RESTRICCIÓN: LA COMPLEJIDAD DEL CASE BY CASE}

Si bien se entiende que el Convenio Europeo dispensa una protección de mínimos ${ }^{42}$ en razón de su carácter de tratado internacional de protección subsidiaria y de la propia existencia del artículo $53 \mathrm{CEDH}$ donde se recoge la cláusula de mayor protección ${ }^{43}$, parece ser posible considerar que los artículos 8 a 11 CEDH pueden suponer una excepción a esta regla. Excepción que parece justificarse, precisamente, en la inclusión de las cláusulas de restricción en la configuración del Convenio y en cómo el TEDH las ha interpretado. Sobre esto, es

39 VAN Rijn, A., «Chapter 14. Freedom of expression» en VAN DijK, P.; VAN Hoof, F.; VAN RijN, A.; ZwaAk, L., [Eds.], Theory and Practice of the European Convention on Human Rights, Antwerpen-Oxford: Intersentia, 2017, p. 784. 2014.

40 Sobre la doctrina del efecto desaliento: Asunto Yılmaz Yıldiz y otros c. Turquía, de 14 de octubre de

41 VAN Rijn, A., «Chapter 14. Freedom of expression»... op. cit., p. 784.

42 Aunque es necesario recordar que esta cuestión de que el CEDH dispensa una protección de mínimos es relativa, pues depende del derecho y, sobre todo, del Estado afectado: el estándar mínimo implementado por el TEDH puede ser un estándar máximo según el Estado en cuestión.

43 A este respecto, García Roca, J., «El preámbulo contexto hermenéutico del Convenio: un instrumento constitucional del orden público europeo», García Roca J. y SANTOlaya Machetti, P., La Europa de los Derechos, CEPC, Madrid, 2014. p. 27. También: García Roca, J., La transformación constitucional del Convenio Europeo de Derechos Humanos, Civitas, Pamplona, 2019. 
necesario tener en cuenta que el Tribunal sigue una dinámica case by case a la hora de interpretar el CEDH: no realiza una interpretación abstracta, sino que responde a un caso concreto, aplicando y desarrollando los derechos en función de las circunstancias particulares ${ }^{44}$. Esta interpretación tópica ha dado lugar a una jurisprudencia prolífica y en constante evolución que ha sido tildada por la doctrina de dinámica, constructiva y evolutiva ${ }^{45}$.

En las próximas líneas se pretende hacer un repaso por las cuestiones comunes de las cláusulas contenidas en los párrafos segundos de los artículos 8 a 11 $\mathrm{CEDH}$, no con ánimo de sintetizar toda la jurisprudencia del TEDH al respecto $^{46}$, sino de intentar poner de relieve las cuestiones interpretativas más complejas.

\section{La injerencia pública en el ejercicio de los derechos}

¿Cómo se constituye la injerencia de la autoridad pública en los derechos reconocidos en los artículos 8 a $11 \mathrm{CEDH}$ ? El Convenio Europeo no recoge en ninguna de sus disposiciones la definición de la injerencia pública en el ejercicio de los derechos. Es más, parece posible decir que, dada la dinámica case by case seguida por el TEDH, definir cómo se constituyen las posibles injerencias no es una preocupación, pues el Tribunal decidirá en cada caso concreto, a través de una evaluación empírica, si ha existido o no interferencia pública en el ejercicio del derecho con base en dos cuestiones: si existe infracción del derecho convencional y cuál es el estado de la víctima en relación con la posible vulneración ${ }^{47}$.

La dinámica case by case seguida por el Tribunal dificulta en gran medida la posibilidad de establecer un estándar concreto sobre la constitución de la injerencia pública en el ejercicio de los derechos, especialmente porque, como se ha dicho, no parece ser una cuestión de preocupación para este órgano. Ahora bien, Coussirat-Coustere subraya algunas nociones generales que permiten identificar cuándo nos encontramos ante una injerencia de la autoridad pública ${ }^{48}$.

44 Sobre esto: Roagna, I, Protecting..., op. cit., pp. 12, 27, 88.

45 En este sentido, Sudre, F., «Rapport introductif. La «construction» par le juge européen du droit au respect de la vie privée», en SUDRE, F., Le droit au respect de la vie privée au sens de la Convention européenne des droits de l'homme, Nemesis Bruyllant, Bruxelles, 2005, pp. 11-33.

46 A este respecto, son muy valiosos los estudios realizados en los siguientes comentarios sistemáticos al CEDH: García Roca J. y Santolaya Machetti, P., La Europa de los Derechos. Centro de Estudios Políticos y Constitucionales, Madrid, 2014; Pettiti, L.E.; Decaux, E.; Imbert, P.H., La Convention Européenne des droits de l'homme, Economica, Paris, 1999; Harris, D.J.; O’Boyle, M.; Bates, E.P.; Buckley, C.M., Law of the European Convention on Human Rights, Oxford University Press, Oxford, 2014; Lasagabaster Herrarte, I. [Dir.], Convenio Europeo de Derechos Humanos. Comentario sistemático, Thompson Reuters Civitas, Pamplona, 2015.

47 Coussirat-Coustere, V., «Article 8 \$ 2..., op. cit., pp. 328-331.

48 Idem. 
En primer lugar, es necesario que la actuación que constituye la injerencia sea imputable al Estado. Esto es, una actuación imputable a sus órganos o a sus agentes en ejercicio de sus funciones ${ }^{49}$.

En segundo lugar, debe tenerse en cuenta que el TEDH ha establecido que una medida adoptada en virtud de un reglamento que no entra dentro del ámbito de aplicación del Convenio no puede constituir una injerencia ${ }^{50}$. Esto es, se exige que la norma nacional aplicable al caso pueda encuadrarse materialmente en uno de los artículos del Convenio. El autor cuestiona la argumentación del TEDH y entiende que si bien la interferencia puede no venir dada por el ámbito material de la norma, sí deben tenerse en cuenta los efectos que la misma puede producir en el derecho garantizado ${ }^{51}$. Y en este sentido resuelve el TEDH en el Asunto Sidabras y Dziautas contra Lituania ${ }^{52}$, donde si bien recuerda que el acceso a la función pública como tal no puede ser la base de una queja en virtud del Convenio ${ }^{53}$, sí puede entenderse que una prohibición amplia para ocupar un puesto de trabajo en el sector privado afecta a la vida privada $^{54}$ puesto que la misma puede tener efectos importantes en las relaciones personales y profesionales del justiciable, así como en sus posibilidades de subsistencia ${ }^{55}$.

En tercer lugar, de acuerdo con Coussirat-Coustere, la existencia de una injerencia presupone que se ha tomado una decisión que afecta a una persona y la eleva al estado de víctima. En este ámbito, el TEDH ha determinado que es posible que en ciertos casos la mera existencia de una ley sea suficiente para que exista injerencia en los derechos de los sujetos pasivos de la misma ${ }^{56}$.

En cuarto lugar, el autor reflexiona sobre si la expresión «injerencia» implica un acto público positivo, una negligencia o una abstención ${ }^{57}$. Es decir, qué debe entenderse por injerencia a la luz de la naturaleza de las obligaciones del Estado. De

49 No obstante, los poderes privados no quedan exentos de la posibilidad de control convencional. Véase, por ejemplo, el Asunto Bărbulescu c. Rumanía, STEDH de enero de 12 de enero de 2016, relativo a la monitorización de las comunicaciones de empleados por parte de empresas privadas.

50 A este respecto, el TEDH se ha pronunciado en casos relativos al artículo $10 \mathrm{CEDH}$, algunos de ellos en conexión con el artículo $8 \mathrm{CEDH}$, y el artículo $14 \mathrm{CEDH}$ en relación con el artículo $8 \mathrm{CEDH}$. Cfr. Asuntos Glasenapp c. Alemania, STEDH de 28 de agosto de 1986, §§50-53; Koisek c. Alemania, STEDH de 28 de agosto de 1986, §\$36-39; Leander c. Suecia, STEDH de 26 de marzo de 1987, §79. En estas sentencias el TEDH determina que no existe dentro del ámbito de protección del Convenio un derecho de acceso a la administración pública, esto es, a ser funcionario y que, por ello, las normas relativas al nombramiento de funcionarios públicos no pueden constituir una injerencia en los derechos del Convenio.

51 Coussirat-Coustere, V., «Article 8 \$ 2... op. cit. p. 329.

52 STEDH de 27 julio 2004.

53 Asunto Sidabras y Dziautas contra Lituania, $\$ 46$.

54 Ibid, $\$ 47$.

55 «The ban has, however, affected their ability to develop relationships with the outside world to a very significant degree and has created serious difficulties for them in terms of earning their living, with obvious repercussions on the enjoyment of their private lives.» Asunto Sidabras y Dziautas contra Lituania, $§ 48$.

56 Así se determina en los Asuntos Klass y otros c. Alemania, STEDH de 6 de septiembre de 1978, \$41; Halford contra Reino Unido, STEDH de 25 junio 1997, \$56.

57 Coussirat-Coustere, V., «Article 8 \$ $2 \ldots$ op. cit. p. 329. 
una parte, el TEDH ha establecido que la formulación de los artículos 8 a 11 CEDH supone que el Estado no puede interferir en el ejercicio de ese derecho más que de acuerdo con los términos que estrictamente establece el párrafo segundo de esos artículos porque su esencia es proteger al individuo frente a injerencias arbitrarias de los poderes públicos ${ }^{58}$. Por tanto, el TEDH parece configurar un deber general de abstención por parte de los Estados salvo en las excepciones reguladas en el párrafo segundo. De otra parte, debe tenerse en cuenta que, en principio, el párrafo segundo no incluye la negativa estatal a actuar o legislar, pero esa abstención por parte del Estado puede constituir la vulneración de sus obligaciones positivas inherentes a su deber de garantizar los derechos reconocidos en el párrafo primero ${ }^{59}$. Es decir, la obligación negativa que constituye el deber de abstención del Estado a la que se aludía antes no le exime de asumir y ejercer las obligaciones positivas que el respecto efectivo a los derechos reconocidos en el artículo $8 \mathrm{CEDH}$ implica ${ }^{60}$. Esto implica, por tanto, la existencia de responsabilidad del Estado por omisión: el Estado no solo responde cuando la injerencia es activa, esto es, cuando limita o restringe el derecho, sino cuando su propio ordenamiento jurídico carece de las herramientas necesarias para garantizar la efectividad del derecho convencional ${ }^{61}$.

En quinto lugar, la injerencia debe ser proyectarse sobre el titular del dere$\mathrm{cho}^{62}$, un familiar o un allegado. Como se ha mencionado, estas restricciones, y por ende las injerencias, pueden presentarse de múltiples formas: formalidades, condiciones, restricciones o sanciones ${ }^{63}$. A este respecto, Coussirat-Coustere se plantea si una restricción debe alcanzar un cierto umbral para considerarse como injerencia ${ }^{64}$. En principio, parece posible afirmar que todas las restricciones, sean o no sanciones, sean fuertes o débiles e, incluso, la mera amenaza de sanción, pueden ser una injerencia ${ }^{65}$. Ahora bien, esto también implica que cuando la norma estatal no impone una restricción explícita, sino que solo incita a ello o prohíbe sin sancionar, su calificación como injerencia resulta complicada porque sus consecuencias negativas dependen del particular ${ }^{66}$.

58 Caso Lingüístico Belga, $\$ 7$.

59 Entre otras, Marcx c. Bélgica, STEDH de 13 de junio de 1979. Sobre obligaciones positivas del Estado y Convenio Europeo de Derechos Humanos véase Carmona Cuenca, E., «Derechos sociales de prestación y obligaciones positivas del Estado en la jurisprudencia del Tribunal Europeo de Derechos Humanos», Revista de Derecho Político, n. ${ }^{\circ} 100,2017$,pp. 1209-1238.

60 Marcx c. Bélgica, $\$ 31$.

61 Esto se pone manifiesto, por ejemplo, en Iglesias Gil y A.U.I. contra España (STEDH de 29 de abril de 2003), donde el TEDH destaca cómo la carencia normativa del propio ordenamiento jurídico español en relación con regulación penal de la sustracción internacional de menores hace incurrir al Estado en una vulneración del artículo $8 \mathrm{CEDH}$.

62 Coussirat-Coustere, V., «Article $8 \$ 2 \ldots$ ob.cit. p. 330.

63 Coussirat-Coustere, V., «Article 8 \$2 ... ob.cit. p. 330 en relación con el artículo 10 CEDH y el Asunto Ezelin c. Francia, STEDH de 26 de abril de 1991, \$39.

64 Coussirat-Coustere, V., «Article 8 \$ $2 \ldots$... ob.cit. p. 330.

65 Asunto Ezelin c. Francia, $\$ 53$ y Asunto A. Sigurjonsson contra Islandia, STEDH de 30 junio 1993, $\$ 36$.

66 Así, por ejemplo, en el Caso Lingüístico Belga, el TEDH afirmó que las normas legales belgas que establecían la enseñanza pública solo en holandés no vulneraban el artículo $8 \mathrm{CEDH}$ porque los menores 


\section{Previsión legal de la medida: in accordance with the law or prescribed by law}

La primera exigencia para que una medida que restrinja el ejercicio del derecho sea legítima coincide con el llamado principio de juridicidad o legalidad de los ordenamientos jurídicos internos de los Estados contratantes ${ }^{67}$. Las expresiones «accordance with the law» $\mathrm{y}$ «prescribed by the law» han sido utilizadas de manera equivalente por el TEDH a pesar de las sutiles diferencias entre ellas. El texto del Convenio Europeo establece, en el apartado 2 del artículo 8, «t th here shall be no interference by a public authority with the exercise of this right except such as is in accordance with the law...». En cambio, la expresión «prescribed by law» es propia de los artículos 9 a $11 \mathrm{CEDH}^{68}$. Harris, O’boyle y Warbrick inciden en cómo «accordance with the law» implica que la medida no sea contraria a la ley, mientras que «prescribed by law» lleva implícita la necesidad de una autorización legal, esto es, una previsión legal concreta ${ }^{69}$. Esta diferencia parecería apuntar a que en los casos en que sea aplicable el artículo $8 \mathrm{CEDH}$, la medida que restrinja alguno de los derechos reconocidos en este artículo requeriría, únicamente, su compatibilidad con el ordenamiento jurídico (accordance to the law) y no una ley concreta que prevea esa medida restrictiva (prescribed by law). Pero ya en 1979, el TEDH indicó que cualquier injerencia en un derecho fundamental debe estar justificada mediante una norma que la prevea, siendo insuficiente el argumento de la compatibilidad con el ordenamiento jurídico ${ }^{70}$. Por ello, el Tribunal estableció que ambas expresiones deben entenderse como equivalentes y ser leídas en el mismo sentido, exigiendo que los Estados dispongan de una ley específica o de un régi-

francoparlantes de la región podían acudir a centros privados. A pesar de reconocer que esto tenía un impacto en la vida familiar derivada de la posible insuficiencia de medios económicos para costear esos centros, el TEDH consideró que la vida familiar no se veía afectada porque el artículo 8 CEDH no garantiza el derecho a ser educado en el idioma de los padres por las autoridades públicas o con su ayuda. Cfr. Caso Lingüístico Belga, $\$ 7$

67 Cfr. Arzoz Santisteban, X., «Artículo 8: Derecho al respeto de la vida privada y familiar», en Lasagabaster Herrarte, I. [Dir.], Convenio Europeo de Derechos Humanos. Comentario sistemático, Thompson Reuters Civitas, Pamplona, 2015, p. 106.

68 «The expression «prescribed by law» appears in paragraph 2 of Articles 9, 10 and 11 (art. 9-2, art. 10-2, art. 11-2) of the Convention, the equivalent in the French text being in each case "prévues par la loi». However, when the same French expression appears in Article 8 (2) (art. 8-2) of the Convention, in Article 1 of Protocol No. 1 (P1-1) and in Article 2 of Protocol No. 4 (P4-2), the English text as «in accordance with the law», «provided for by law» and «in accordance with law», respectively. Thus confronted with versions of a law-making treaty which are equally authentic but not exactly the same, the Court must interpret them in a way that reconciles them as far as possible and is most appropriate in order to realise the aim and achieve the object of the treaty» (Asunto Sunday Times c. Reino Unido, STEDH de 26 de abril de 1979, \$48).

69 Harris, D.J.; O’Boyle, M.; Bates, E.P.; Buckley, C.M., Law of the European Convention on Human Rights, Oxford University Press, Oxford, 2014, p. 506.

70 Asuntos Sunday Times c. Reino Unido, STEDH de 26 de abril de 1979, §48; Silver y otros c. Reino Unido, STEDH de 25 de marzo de 1983, §§85-86, y Malone c. Reino Unido, STEDH de 2 de agosto de 1984, §§66-67. Cfr. Arzoz Santisteban, X., «Artículo 8...», op. cit. p. 340; Harris et al., Law of the European Convention..., op. cit. p. 506. 
men de autorización predefinido que contemple la injerencia en el derecho fundamental ${ }^{71}$. Como se verá continuación, estamos ante un principio de legalidad intenso que exige calidad, previsibilidad y certeza de las normas y que está basado en la interdicción de leyes caracterizadas por su vaguedad ${ }^{72}$.

Pero, ¿qué debe entenderse por ley? El TEDH ha apuntado que la noción de «ley» es un concepto autónomo ${ }^{73}$ que va a depender de las singularidades individuales de los ordenamientos internos ${ }^{74}$. La existencia de estas singularidades ha llevado al TEDH a integrar en su jurisprudencia los requisitos que deben reunir esas normas que restrinjan derechos fundamentales para que cumplan con la exigencia de previsión legal requerida por los párrafos segundos de los artículos 8 a $11 \mathrm{CEDH}$ y, con ello, justifiquen la injerencia de la autoridad pública en el ejercicio del derecho ${ }^{75}$.

En el marco de estas singularidades individuales se plantea un interrogante: ¿pueden las normas de Common Law cumplir la exigencia de previsión legal? Esta pregunta que se analizó en el Asunto The Sunday Times c. Reino Unido, en el que se cuestionó si la exigencia de previsión legal incluía o no las normas no escritas. De acuerdo con la interpretación del TEDH, que la ley que ampara la injerencia sea resultado del Common Law y no del procedimiento legislativo parlamentario no puede ser óbice para que se entienda cumplida la exigencia de previsión legal, pues lo contrario implicaría privar a un Estado de la protección del Convenio ${ }^{76}$. Esta reflexión ha permitido que el TEDH articule un concepto material, y no

71 «The Court would reiterate its opinion that the phrase «in accordance with the law» does not merely refer back to domestic law but also relates to the quality of the law, requiring it to be compatible with the rule of law, which is expressly mentioned in the preamble to the Convention [...]. The phrase thus implies —and this follows from the object and purpose of Article 8 (art. 8) - that there must be a measure of legal protection in domestic law against arbitrary interferences by public authorities with the rights safeguarded by paragraph 1 (art. 8-1)[...]». (Asunto Malone c. Reino Unido, STEDH de 2 de agosto de 1984, §67).

72 Ver Asunto Haldford c. Reino Unido, STEDH de 25 de junio de 1997, \$49.

73 Harris et al., Law of the European Convention..., op. cit. p. 506.

74 En relación con esta cuestión es interesante el trabajo de Susana Huerta sobre el contenido del principio de legalidad penal. Ver Huerta, S., «El contenido debilitado del principio europeo de legalidad penal (Art. 7 CEDH y art. 4 P7)», en García Roca, J. y Santolaya, P., La Europa de los Derechos, CEPC, Madrid, 2014, pp. 399-427.

75 En contraposición, la Corte Interamericana, en el marco del artículo 30 de la Convención Americana de Derechos Humanos - equivalente al artículo $18 \mathrm{CEDH}$ y, por tanto, relativo a los límites a las restricciones de los derechos - adopta un concepto totalmente formal de ley según el cual solo es posible entender como «ley» aquellos actos normativos emanados del poder legislativo democráticamente elegido y promulgados por el poder ejecutivo, de acuerdo con los principios y órganos constitucionalmente establecidos. Véase Corte IDH. La expresión «Leyes» en el artículo 30 de la Convención Americana sobre Derechos Humanos. Opinión Consultiva OC-6/86 de 9 de mayo de 1986. Serie A No. 6. Disponible en: https://www.corteidh.or.cr/ docs/opiniones/seriea_06_esp.pdf

76 «The Court observes that the word «law» in the expression «prescribed by law» covers not only statute but also unwritten law. Accordingly, the Court does not attach importance here to the fact that contempt of court is a creature of the common law and not of legislation. It would clearly be contrary to the intention of the drafters of the Convention to hold that a restriction imposed by virtue of the common law is not «prescribed by law» on the sole ground that it is not enunciated in legislation: this would deprive a common-law State which is Party to the Convention of the protection of Article 10 (2) (art. 10-2) and strike at the very roots of that State's legal system.» (Asunto The Sunday Times c. Reino Unido, STEDH de 29 de abril de 1979, §47). 
formal, de ley que implica que normas jerárquicamente inferiores a la ley entendida esta como norma inmediatamente supeditada a la Constitución que emana de un Parlamento- y la doctrina jurisprudencial de los tribunales superiores - tribunales supremos y constitucionales-, que interpretan las normas, puedan cubrir la exigencia de previsión legal ${ }^{77}$. Esto es, la exigencia de previsión legal no se agota en el texto escrito, sino que se extiende a su interpretación por parte de los órganos judiciales competentes.

El desarrollo por parte del TEDH de la exigencia de previsión legal no se agota en cuestiones formales ${ }^{78}$. De acuerdo con la jurisprudencia del Tribunal Europeo, cualquier interferencia de una autoridad pública en los derechos del artículo $8 \mathrm{CEDH}$ no exige únicamente la existencia y el cumplimiento de la legislación nacional, sino que impone requisitos de calidad de esa ley y su compatibilidad con el Estado de Derecho: «According to the Court's well-established case-law, this expression does not only necessitate compliance with domestic law, but also relates to the quality of that law, requiring it to be compatible with the rule of law.» (Asunto Haldford c. Reino Unido, STEDH de 25 de junio de 1997, §49).

Ahora bien, ¿qué se considera una ley de calidad? El TEDH ha configurado tres requisitos que permiten valorar la calidad de la ley de acuerdo con las exigencias del apartado segundo del artículo $8 \mathrm{CEDH}$ : la claridad de la norma, la accesibilidad de la norma al ciudadano y la precisión en su formulación ${ }^{79}$. El TEDH exige una norma clara y no discrecional: la legislación nacional debe indicar, con una claridad razonable, cuál es el alcance y la forma en la que sus autoridades pueden ejercer esa discrecionalidad ${ }^{80}$ Esto implica que, en todo caso, el ciudadano afectado por la norma debe tener una información adecuada y suficiente sobre las normas aplicables a un caso concreto. Pero además, una norma no podrá considerarse como ley si no ha sido formulada con una precisión suficiente que permita al ciudadano regular su propia conducta. Es decir, el ciudadano debe poder prever, de forma razonable, las consecuencias que tendrá su conducta. No obstante, el TEDH no exige certeza, pero sí evitar los términos vagos e imprecisos ${ }^{81}$.

77 «Moreover, the Court cannot ignore the opinions of academic writers and the Federal Court's caselaw on the question, which the Government cited in their memorial [...] In relation to paragraph 2 of Article 8 of the Convention and other similar clauses, the Court has always understood the term «law» in its «substantive» sense, not its «formal one», and has in particular included unwritten law therein [...]» (Asunto Kopp c. Suiza, STEDH de 5 de marzo de 1998, §60).

78 Cfr. Arzoz Santisteban, X., «Artículo 8...», op. cit., p. 342; Harris et. al., Law of the European Convention..., op. cit., p. 506.

79 Asunto The Sunday Times c. Reino Unido, STEDH de 29 de abril de 1979, \$49; Silver y otros c. Reino Unido, STEDH de 25 de marzo de 1983, §87. Sobre esta cuestión destaca EndicotT, T. A. O., Vagueness in Law, Oxford University Press, Oxford, 2000.

80 Asuntos Domenichini c. Italia, STEDH de 15 de noviembre de 1996, §33; Nurzyński c. Polonia, STEDH de 21 de diciembre de 2010, §36; Piechowicz c Polonia, STEDH de 17 de abril de 2012, \$212.

81 «In the Court's opinion, the following are two of the requirements that flow from the expression «prescribed by law». Firstly, the law must be adequately accessible: the citizen must be able to have an indication that is adequate in the circumstances of the legal rules applicable to a given case. Secondly, a norm cannot be regarded 


\section{Las finalidades legítimas de la medida}

La injerencia de la autoridad pública en el ejercicio de los derechos reconocidos por los artículos 8 a 11 CEDH debe estar justificada en alguna de las previsiones ya señaladas ${ }^{82}$. La amplitud de estas previsiones es tan grande que el margen de interferencia de los Estados y sus posibilidades de definir una argumentación plausible parecen incrementarse ${ }^{83}$. Por ello, es frecuente que los demandantes rechacen la legitimidad de las interferencias públicas, argumentando que los objetivos declarados por el Estado solo son limitaciones al derecho impuestas para fines diferentes de los aludidos e inadmisibles en el marco de protección que intenta garantizar el $\mathrm{CEDH}^{84}$.

Frente a esto, la interpretación del TEDH se construye sobre la base de la restricción ${ }^{85}$. El Tribunal ha afirmado que la enumeración de excepciones contenidas en los artículos 8 a 11 CEDH debe entenderse como exhaustiva y restrictiva ${ }^{86}$, de manera que la limitación de alguno de los derechos protegidos por este artículo deberá estar vinculada a alguno de esos objetivos ${ }^{87}$. Sobre este particular, Coussirat-Coustere incide en que la formulación negativa del apartado segundo permite entender, precisamente, que nos encontramos ante una enumeración limitativa o restrictiva. No obstante, parece que existen algunas excepciones a esta restricción: el interés superior del menor en el ámbito del derecho al respeto de la vida fami$\operatorname{liar}^{88}$ y el régimen de autorizaciones de los sistemas de radiodifusión ${ }^{89}$.

as a «law» unless it is formulated with sufficient precision to enable the citizen to regulate his conduct: he must be able — if need be with appropriate advice — to foresee, to a degree that is reasonable in the circumstances, the consequences which a given action may entail. Those consequences need not be foreseeable with absolute certainty: experience shows this to be unattainable. Again, whilst certainty is highly desirable, it may bring in its train excessive rigidity and the law must be able to keep pace with changing circumstances. Accordingly, many laws are inevitably couched in terms which, to a greater or lesser extent, are vague and whose interpretation and application are questions of practice». (Asunto The Sunday Times c. Reino Unido, STEDH de 29 de abril de 1979, §49).

82 Sobre las finalidades legítimas de la intervención pública en el ejercicio de los derechos merece que se recuerde el trabajo de Bernal Pulido, C., El principio de proporcionalidad y los derechos fundamentales, CEPC, Madrid, 2007. En particular, el tratamiento que hace del «subprincipio de idoneidad» (pp. 693-739).

83 Harris et al., Law of the European Convention..., op. cit., pp. 509-510.

84 Como apuntan Harris, O’Boyle y Warbrick, la argumentación de los demandantes en estos casos se sustenta sobre la mala fe del Estado, esto es, el poder público sustenta su interferencia en una razón que no es la razón real de la misma. En estos supuestos, el TEDH parece reticente a aceptar estas consideraciones, aunque han tenido éxito en algunos casos (p.e. Asunto Moscow Branch Of The Salvation Army c. Russia, STEDH de 5 de octubre de 2006, §97). Cfr. Harris et al., Law of the European Convention..., op. cit,. p. 509. Ver, además, Asunto Campbell c. Reino Unido, STEDH de 25 de marzo de 1992, §\$39-41.

85 Asunto SAS c. Francia, STEDH de 1 de julio de 2014, $\$ \$ 113-114$.

86 Asuntos Mykhaylivska Parafiya c. Ucrania, STEDH de 14 de junio de 2007, §132, Nolan y K. c. Rusia, STEDH de 12 de febrero de 2009, §73.

87 Asunto SAS c. Francia, STEDH de 1 de julio de 2014, $\$ 113$.

88 Cfr. Almeida, S., Familia a la luz del Convenio Europeo... ob.cit., p. 108.

89 Cfr. Coussirat-Coustere, V., «Article 8 \$2 ..», op. cit., p. 336. Ver, además, Asunto Informationsverein Lentia y otros c. Austria, STEDH de 24 de noviembre de 1993, §32-34. Asimismo, sobre esta cuestión, ver García Roca, J., «¿Existe un derecho a crear la televisión?», Derecho Privado y Constitución, n. ${ }^{\circ} 10,1996$, pp. $147-182$. 
Por otro lado, parece necesario apuntar que, en todo caso, la carga de probar que la actuación de la autoridad pública se encuadra en alguno de los objetivos legítimos enumerados en este apartado segundo del artículo $8 \mathrm{CEDH}$ recae sobre el Estado demandado ${ }^{90}$. A este respecto, Harris, O’Boyle y Warwrick reflexionan sobre la importancia de la correcta identificación del objetivo que sustenta la injerencia pública. Es decir, no solo es necesario que la interferencia de los poderes públicos se encuadre en alguno de los objetivos que recogen los apartados segundos de los artículos 8 a $11 \mathrm{CEDH}$, sino que dicho objetivo debe ser adecuado y estar correctamente identificado ${ }^{91}$. De acuerdo con los autores, el TEDH no concede suficiente importancia a esta cuestión, pues es frecuente que los Estados citen más de un objetivo que ampare su actuación sin que el Tribunal se pronuncie sobre todos. Esto es, cuando los Estados apuntan más de una razón para legitimar su injerencia, el Tribunal no suele reflexionar sobre todas ellas: cuando una de esas razones es adecuada en el marco establecido por los artículos 8 a $11 \mathrm{CEDH}$, el TEDH decidirá que la actuación estatal será legítima. Pero esta dinámica también puede funcionar en contra del Estado y tener el resultado contrario: el TEDH puede decidir que la actuación es ilegítima pronunciándose únicamente sobre una de las razones aludidas por el Estado para justificar su actuación ${ }^{92}$.

\section{Necesidad de la medida en una sociedad democrática}

Aunque un Estado demandado logre convencer al TEDH de que sus medidas restrictivas de los derechos protegidos por el artículo $8 \mathrm{CEDH}$ están previstas en una norma que cumple los requisitos y exigencias del Tribunal y que, además, se fundamenta en uno de los objetivos legítimos enumerados en el apartado segundo de este artículo, necesita cumplir una tercer requerimiento: que la medida sea necesaria y adecuada en una sociedad democrática. Para determinar esta necesidad, el TEDH ha establecido que es necesario equilibrar los intereses del Estado contratante y los derechos del demandante. Pero, además, ha sido necesario que el Tribunal defina qué se debe entenderse a partir de la expresión «necesaria en una sociedad democrática».

De una parte, el TEDH ha establecido que el adjetivo «necesario» no puede considerarse sinónimo de «indispensable», ni es tan flexible como «admisible», «ordinario», «útil», «razonable» o «deseable» ${ }^{93}$. Así, la expresión «necesaria en

90 Cfr. Almeida, S., Familia a la luz del Convenio Europeo..., op. cit., p. 108.

91 HARris and others, Law of the European Convention..., op. cit., p. 510.

92 Harris, O'BOYLE y WARWRICK cuestionan la equidad de esta dinámica convencional, que, en ciertos casos, parece ayudar al TEDH a evitar pronunciarse sobre cuestiones difíciles. Cfr. HARRIS and others, Law of the European Convention..., op. cit., p. 510.

93 Asunto Handyside c. Reino Unido, STEDHS de 7 de diciembre de 1976, §48. 
una sociedad democrática» quiere decir que para que la injerencia de la autoridad pública pueda ser compatible con el Convenio debe corresponder a una «necesidad social apremiante»y ser «proporcional al objetivo legítimo perseguido», puesto que dos de las características del CEDH son la tolerancia y la amplitud de miras ${ }^{94}$. En todo caso, la carga probatoria de la existencia de esa necesidad social apremiante que sustente la injerencia del poder público corresponde al Estado demandado ${ }^{95}$.

Como se ha visto anteriormente, la convencionalización de la necesidad de la medida en una sociedad democrática tenía el objetivo de dotar de cierta amplitud a las cláusulas de restricción incluidas en los artículos 8 a $11 \mathrm{CEDH}$. Y es precisamente aquí donde las diferencias entre los derechos protegidos por estos artículos cobran un calibre especial. De una parte, la proyección social y cultural de la protección de la vida privada y familiar (art. $8 \mathrm{CEDH}$ ) y de la libertad de pensamiento, conciencia y religión (art. $9 \mathrm{CEDH}$ ) da lugar a que estos derechos sean un caldo de cultivo importante para el desarrollo del margen de apreciación nacional, puesto que son derecho con una alta incidencia en cuestiones morales ${ }^{96}$. Este desarrollo se sustenta, entre otras cuestiones, en las dificultades para establecer un marco común normativo en relación con estos derechos derivadas de la heterogeneidad de los países europeos ${ }^{97}$. Así, en estos derechos, existe una cierta tendencia a extender el margen de apreciación de los Estados y, con ello, la legitimidad de la injerencia pública en el ejercicio del derecho.

En cambio, la libertad de expresión (art. $10 \mathrm{CEDH}$ ) y el derecho de reunión y asociación (art. $11 \mathrm{CEDH}$ ) gozan de una vinculación esencial con el mantenimiento de la democracia al ser garantía de una opinión pública libre que pueda participar en la vida pública ${ }^{98}$. Una vinculación que garantiza un margen de apreciación estrecho para los Estados en pro de garantizar la esencialidad de estos derechos ${ }^{99}$.

\section{UN ÚLTIMO APUNTE: EL LÍMITE A LAS RESTRICCIONES DEL ARTÍCULO $18 \mathrm{CEDH}$}

Ya se adelantó en el epígrafe dedicado a los trabajos preparatorios cómo la configuración de las cláusulas de restricción en el CEDH cuenta con una

94 Asunto Dudgeon c. Reino Unido, STEDH de 22 de octubre de 1981, §§51-53.

95 Asunto Piechowicz c. Polonia, STEDH de 17 de abril de 2012, §212.

96 Cfr. García Roca, J., El margen de apreciación nacional en la interpretación del Convenio Europeo de Derechos Humanos, Civitas, Pamplona, 2010, p. 273.

97 Para un estudio completo del margen de apreciación nacional y su aplicabilidad ver: GARCía RocA, J., El margen..., op. cit., García RoCA, J., La transformación constitucional del Convenio..., op. cit., pp. 104 y ss.

98 Sobre el desarrollo convencional de estos derechos ver, entre otros: Bustos GisBERT, R., «Los derechos de libre comunicación en una sociedad democrática» y Bilbao UBILlos, J.M., «Las libertades de reunión y asociación: algunas vacilaciones en una trayectoria de firme protección», ambos en García Roca, J. y Santolaya, P., La Europa de los Derechos, CEPC, Madrid, 2014, pp. 473-552.

99 García Roca, J., La transformación constitucional del Convenio..., op. cit., p. 118. 
«contra-cláusula»: la limitación general a la aplicación de las restricciones que incluye el artículo 18 del Convenio Europeo: "Las restricciones que, en los términos del presente Convenio, se impongan a los citados derechos y libertades no podrán ser aplicadas más que con la finalidad para la cual hayan sido previstas.»

La funcionalidad y alcance de este artículo han sido muy cuestionados debido a su redacción abstracta, la falta de explicación sobre su intencionalidad en los trabajos preparatorios y la ausencia de un precedente similar en otros instrumentos internacionales de derechos humanos ${ }^{100}$. Pero, como destaca Pablo Santolaya, y se extrae de los trabajos preparatorios del $\mathrm{CEDH}^{101}$, la vinculación de este artículo con los derechos reconocidos en los artículos 8 a $11 \mathrm{CEDH}$ es innegable ${ }^{102}$.

El artículo 18 contiene una cláusula contraria a la desviación de poder ${ }^{103}$ cuyo objetivo parece ser el evitar el abuso de los Estados a la hora de imponer restricciones al ejercicio de los derechos más allá de lo establecido en las disposiciones del $\mathrm{CEDH}^{104}$.

El desarrollo jurisprudencial que el TEDH ha hecho de este artículo ha sido ciertamente limitado ${ }^{105}$ y la doctrina lo ha asimilado a la protección frente al abuso de derecho que recoge el artículo $17 \mathrm{CEDH}^{106}$. Además, se ha entendido que no procede su aplicación autónoma, sino que es una previsión de naturaleza subsidiaria que solo puede invocarse en conexión con otros artículos del CEDH siempre que contengan una previsión restrictiva específica o siempre que se pueda deducir de ellos límites específicos a su ejercicio ${ }^{107}$. No obstante, su función no se limita a aclarar el alcance de las cláusulas de restricción presentes en el CEDH, sino que también goza de una limitada autonomía porque prohíbe expresamente que los Estados puedan restringir los derechos del Convenio para fines no previstos en él, lo que permite entender que existe la posibilidad de que se vulnere el artículo $18 \mathrm{CEDH}$ aunque no se vulnere el artículo junto con el que se invoca ${ }^{108}$.

100 A este respecto Santolaya P., «Limitación de la aplicación de las restricciones de derechos. Art. 18 CEDH (un genérico límite a los límites según su finalidad»), en García Roca, J. y SANTOLAya, P., La Europa de los Derechos, CEPC, Madrid, 2014, p. 657. También Lazcano Brottons, «Artículo 18. Limitación de la aplicación de las restricciones de derechos» en Lasagabaster Herrarte, I. (Dir)., Convenio Europeo de Derechos Humanos. Comentario sistemático, Thompson Reuters Civitas, Pamplona, 2015, pp. 843 y ss.

101 Council of Europe, Vol.4..., op. cit., p. 258.

102 Santolaya P., «Limitación»..., op. cit., p. 658.

103 Lazcano Brottons, «Artículo 18...», op. cit., p. 843.

104 Santolaya P., «Limitación...», op. cit., p. 658.

105 A fecha de este artículo se contabilizan apenas 90 sentencias del TEDH relacionadas con este artículo.

106 Ídem.

107 Ver: Merabishvili contra Georgia, STEDH de 28 de noviembre de 2017, §287. Asimismo, ArAI, Y. y Meese, J., «Chapter 36. Prohibition of misuse power», en VAN DijK, P.; VAN Hoof, F.; Van Rijn, A.; ZwaAk, L. (eds.), Theory and Practice of the European Convention on Human Rights, Intersentia, Antwerpen-Oxford, 2017, pp. 1095 y ss. También Santolaya P., «Limitación...», op. cit., p. 659.

108 Merabishvili contra Georgia, $\$ 288$. 
Esto implica que, como se ha adelantado, la vinculación de este artículo con los artículos 8 a $11 \mathrm{CEDH}$ es inequívoca ${ }^{109}$.

Como se ha mencionado, la jurisprudencia convencional sobre este derecho ha sido bastante reducida, lo que ha dado lugar a un desarrollo más bien limitado. Esto tiene su explicación no solo en la escasez de pronunciamientos, sino en una cierta resistencia por parte del TEDH y de la antigua Comisión a la hora de analizar la aplicabilidad de este artículo. En un primer momento, la Comisión, en su interpretación del artículo $18 \mathrm{CEDH}$, pareció entender que si un Estado se excedía en la aplicación de restricciones a un derecho, la vulneración era del propio derecho y no del artículo $18 \mathrm{CEDH}$, puesto que lo contrario restaría autonomía al propio derecho ${ }^{110}$. Asimismo, el Tribunal tenía una cierta tendencia a asimilar la posición de la Comisión cuando esta desechaba la aplicabilidad del artículo $18 \mathrm{CEDH}^{111}$. En este sentido, el TEDH también ha determinado que si en el marco de análisis del derecho en controversia se determina que la restricción a su ejercicio ha sido legítima, decae la aplicación del artículo $18 \mathrm{CEDH}$, pues no existe extralimitación por parte del Estado que deba analizarse ${ }^{112}$.

Por otro lado, en la evolución jurisprudencial del TEDH se ha puesto de manifiesto la relevancia de construcciones como el principio de proporcionalidad o el margen de apreciación nacional. En general, cuando un Estado se excede en las restricciones impuestas a los derechos, el Tribunal entiende que su actuación no ha sido proporcional y que ha sobrepasado su margen de apreciación, desatendiendo la aplicabilidad del artículo $18 \mathrm{CEDH}$ y, con ello, vaciándolo de contenido $^{113}$. Asimismo, en el caso particular de los artículos 8 a $11 \mathrm{CEDH}$, si el Tribunal determina que la actuación del Estado no ha respetado las exigencias de sus párrafos segundos, entenderá que es innecesario examinar si, además de la vulneración de estos artículos, ha existido vulneración del artículo $18 \mathrm{CEDH}^{114}$. En todo caso, tanto si el TEDH ha determinado la vulneración del derecho como si ha entendido que el mismo no ha sido vulnerado, no verá necesario analizar la posible vulneración del artículo $18 \mathrm{CEDH}$, puesto que entenderá ya ha examinado la cuestión y no es necesario reiterarlo a la luz del artículo $18^{115}$.

109 Es más, tanto Lazcano como Santolaya indican que no es posible la aplicación del artículo 18 CEDH cuando se invocan derechos inderogables, como los recogidos en los artículos 2 y 3 CEDH. Cfr. Lazcano Brottons, «Artículo 18...», op. cit. p. 847; Santolaya P., «Limitación...», op. cit., p. 659.

110 Ver Kamma c. Países Bajos, Informe de la Comisión de 14 de julio de 1974 y reflexión de Santolaya, P., «Limitación...», op. cit., p. 661.

111 Ver, por ejemplo, Akdivar y otros c. Turquía, STEDH de 16 de septiembre de 1996, §99 y Mentes y otros c. Turquía, STEDH de 28 de noviembre de 1997, $\$ 93-96$.

112 Ver: Handyside c. Reino Unido, STEDH de 7 de diciembre de 1976, §68.

113 LazCano BrotTons, «Artículo 18...», op. cit., p. 849.

114 Ver: Craxi c. Italia, STEDH de 17 de julio de 2003, §§85-86.

115 Ver, por ejemplo, Dulaşc. Turquía, STEDH de 30 de enero de 2001, §§70-73. También, Santolaya, P. «Limitación...», op. cit. p. 660. 
No obstante, esta tendencia del Tribunal cuenta con algunas excepciones. En el caso Gusinskiy contra Rusia, de 19 de mayo de 2004, el TEDH declara por primera vez la vulneración del artículo $18 \mathrm{CEDH}$ en relación con el artículo 5 $\mathrm{CEDH}$ y entiende que es posible que una determinada limitación de un derecho pueda ser admisible desde el punto de vista del artículo que lo protege, pero no desde la restricción general del artículo $18 \mathrm{CEDH}^{116}$. Aunque estamos ante un caso puntual ${ }^{117}$, en los siguientes años el TEDH ha declarado en otras ocasiones la vulneración del artículo $18 \mathrm{CEDH}^{118}$, con un cierto desarrollo del mismo y expandiendo su contenido ${ }^{119}$.

En el ámbito que nos ocupa - las cláusulas de restricción de los artículos 8 a 11 CEDH - destaca de manera importante el asunto Navalnyy contra Rusia de 15 de noviembre de 2018. El demandante, un ciudadano ruso, invoca la vulneración del artículo $11 \mathrm{CEDH}$ después de haber sido arrestado en repetidas ocasiones durante la celebración de actos públicos de protesta ${ }^{120}$. Asimismo, argumentó que Rusia había excedido su margen para restringir el ejercicio de sus derechos puesto que las medidas estatales tenían la intención de infligir castigo por sus actividades políticas y desalentar el debate público, dando lugar a la vulneración del artículo $18 \mathrm{CEDH}(\$ \S 156-157)$. Y, efectivamente, el TEDH determina que Rusia había impuesto restricciones al demandante con el propósito ulterior de suprimir el pluralismo político, que es parte de una democracia política efectiva, incurriendo en un abuso de poder que constituía la vulneración del artículo 18 $\mathrm{CEDH}$ en relación con los artículos 5 y 11 del Convenio.

\section{CONCLUSIONES}

La decisión política durante los trabajos preparatorios de incluir cláusulas de restricción en el articulado ha tenido, en estos setenta años de desarrollo del $\mathrm{CEDH}$, una incidencia fundamental en la construcción de la doctrina del margen de apreciación nacional y en el desarrollo de los propios derechos protegidos por los artículos 8 a $11 \mathrm{CEDH}$. Sin estas cláusulas el sistema de protección europeo articulado en torno a este tratado internacional sería muy distinto. No obstante,

116 En este caso, relativo a una detención, se consideró que si bien la detención fue razonable a la luz del artículo $5 \mathrm{CEDH}$, la finalidad de la misma, a la luz del artículo $18 \mathrm{CEDH}$, era incompatible con el propio Convenio. Ver: Gusinskiy c. Rusia, §§73-78.

117 Cfr. Santolaya, P., «Limitación...», op. cit. pp. 662 y ss.

118 Aquí destaca muy especialmente el asunto Merabishvillic. Georgia, de 28 de noviembre de 2017.

119 Sobre este desarrollo jurisprudencial del artículo 5 CEDH y el artículo 18 CEDH es esencial el reciente trabajo de García RocA, J., «El Tribunal Europeo de Derechos Humanos como tribunal electoral y el estatuto de la oposición política», en SÁnchez NAvarro, A. y Fernández, R. (eds.), Reflexiones para una democracia de calidad en la era tecnológica, pendiente de edición. Asimismo, García RocA, J., La transformación constitucional del Convenio..., op. cit., pp. 171-172.

120 También se invoca la vulneración de los artículos 5 y 6 CEDH. 
algunas de las inquietudes que se pusieron de manifiesto durante la elaboración del Convenio han quedado patentes en este tiempo. De una parte, la imposibilidad de prever todas las posibles interferencias que pueden afectar a un derecho. Aunque se hizo un esfuerzo por hacer listas de restricciones, la experiencia de estos setenta años de desarrollo del Convenio ha dejado patente la existencia de excepciones que hacen dudar de que el listado de fines que permiten las interferencias sea cerrado. Más bien, la dinámica case by case constructiva que impregna la jurisprudencia del TEDH y que da lugar a un gran dinamismo interpretativo parece apostar por lo contrario pues, como dice el propio Tribunal, el Convenio «es un instrumento vivo».

De otra parte, la propia estructura que articula estas cláusulas de restricción deja algunas cuestiones en las que parece necesario insistir. En primer lugar, toda restricción a los derechos reconocidos en estos artículos 8 a 11 CEDH requiere una previsión legal. Es decir, las restricciones se rigen por un principio de legalidad que, de acuerdo con el desarrollo jurisprudencial del TEDH, es muy intenso pero no formalista: el objetivo no es exigir que las restricciones estén previstas en leyes formales, sino la interdicción de las leyes vagas. Eso sí, esta flexibilidad va acompañada de tres requisitos de calidad que el TEDH aplica con gran rigor y que están dirigidos a evitar la discrecionalidad de los Estados: las leyes deben ser claras, accesibles a los ciudadanos y precisas.

En segundo lugar, todos estos artículos incluyen un listado de fines legítimos que pueden amparar la restricción al ejercicio de los derechos que reconocen (orden público, seguridad pública, protección de otros derechos, etc.). Pero, como se ha intentado poner de manifiesto, este listado de fines no puede entenderse como una lista cerrada, sino que en varias ocasiones se han utilizado fines no previstos en estos artículos para justificar la restricción del derecho (véase, el interés superior del menor, por ejemplo).

Por último, la exigencia de que la medida restrictiva de derechos sea necesaria en una sociedad democrática. Esto es, que la medida responda a una necesidad social apremiante e intensa. Esta exigencia parece obedecer a un claro objetivo: garantizar que derechos que protegen bienes jurídicos especialmente sensibles — vida privada y familiar (art. $8 \mathrm{CEDH}$ ) y libertad religiosa (art. $9 \mathrm{CEDH})-\mathrm{o}$ especialmente necesarios para el mantenimiento de la democracia - libertad de expresión (art. $10 \mathrm{CEDH}$ ) y derecho de reunión (art. 11 CEDH) - no se vean menoscabados de manera arbitraria y, por ello, queden blindados de manera específica ante el poder público. En este sentido, parece necesario incidir en que el desarrollo jurisprudencial de estos derechos parece apuntar a que no es posible hacer una interpretación literal de estas cláusulas de restricción: los derechos que están sometidos a ellas protegen intereses jurídicos muy abiertos y en constante cambio. Pero, a la vez, esto es lo que hace de ellos derechos susceptibles de intervención pública.

En otro orden de cosas, si bien no se comparten las inclinaciones doctrinales que derivan en entender que el Convenio integra distintos niveles de protección, 
parece necesario hacer algunas precisiones. Por un lado, como se ha intentado esclarecer, la integración en el Convenio de determinados artículos sujetos a restricciones no da lugar a un sistema basado en las jerarquías de derechos, sino a un sistema sometido a ponderaciones en el que prevalecerá un interés u otro atendiendo a la dinámica case by case que caracteriza el desarrollo jurisprudencial del TEDH.

Por otro lado, debe tenerse en cuenta que las cláusulas de restricción no son las únicas cláusulas limitativas en el CEDH. Piénsese, por ejemplo, en las cláusulas de exclusión que contienen los artículos 2 y $4 \mathrm{CEDH}$, en las que se establecen determinados contenidos — como la legítima defensa o el servicio militar obligatorio- que quedan fuera de la protección de los derechos que contienen. Además, y aunque no se ha profundizado en ello porque no era objeto del trabajo, el hecho de que estos artículos 8 a $11 \mathrm{CEDH}$ integren cláusulas específicas de restricción no salva que el resto de derechos del CEDH — salvo la prohibición de tortura del artículo $3 \mathrm{CEDH}$ - se vean sometidos a las limitaciones habituales para los derechos fundamentales y a la aplicación del principio de proporcionalidad cuando existe una injerencia pública en su ejercicio.

Por último, la existencia de las cláusulas de restricción en el Convenio y, de manera particular, la exigencia de que la injerencia pública en el derecho sea necesaria en una sociedad democrática ha permitido un gran desarrollo jurisprudencial en el marco de la aplicación del margen de apreciación nacional y las obligaciones positivas del Estado. Si bien la restricción a los derechos actúa, en parte, como límite a la actuación del Estado, no es menos cierto que las exigencias de garantía al mismo no se limitan a su abstención, sino que exigen su actuación positiva. Este desarrollo contrasta con la escasa aplicación del artículo $18 \mathrm{CEDH}$ que, en los últimos años, está cobrando una tímida fuerza con resoluciones sumamente interesantes en el ámbito de la protección de activistas y opositores. Un artículo previsto como complemento, que, por ahora, nos deja casos casi anecdóticos, pero con gran potencial en este ámbito de las cláusulas de restricción.

$* * *$

TITLE: Restriction clauses in the European Convention on Human Rights

ABSTRACT: This paper is intended to analyse the system of restrictions on the exercise of rights provided by articles 8 to 11 of the European Convention on Human Rights. Thus, the principal aim is reflecting on the impact of these restriction clauses, their case-law development by the European Court of Human Rights and their meaning on the construction of the Council of Europe Human Rights System.

RESUMEN: El presente trabajo pretende analizar el sistema de restricciones al ejercicio de los derechos previsto en los artículos 8 a 11 del Convenio Europeo de Derechos Humanos. Así, el objetivo principal es reflexionar sobre la incidencia de estas cláusulas de restricción, su desarrollo jurisprudencial por parte del Tribunal Europeo de Derechos Humanos y su significado en la construcción del sistema de derechos humanos del Consejo de Europa. 
KEY WORDS: European Convention on Human Rights, interference by a public authority, limitation on use of restrictions on rights, necessary in a democratic society, restrictions.

Palabras Clave: Convenio Europeo de Derechos Humanos, injerencia de la autoridad pública, limitación de las restricciones en los derechos, necesidad en una sociedad democrática, restricciones.

FECHA DE RECEPCIÓN: 01.01.2020 FECHA DE ACEPTACIÓN: 26.01.2021 